\title{
Reappraisal of Functional Importance of Coronary Collateral Circulation
}

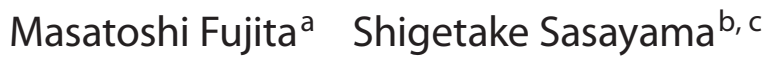 \\ ${ }^{a}$ Human Health Sciences, Kyoto University Graduate School of Medicine, and b Faculty of Life and Medical Science, \\ Doshisha University, Kyoto, and 'Daijukai Hospital, Hirakata, Japan
}

\section{Key Words}

Coronary collateral development • Coronary collateral regression - Myocardial ischemia - Myocardial viability • Repeated coronary occlusion

\begin{abstract}
Coronary collateral circulation (CCC) is defined as an alternative blood-conveying circuit to the ischemic myocardium supplied by a jeopardized coronary artery. Accumulating evidence on CCC and its functional role has been derived from basic and clinical studies over several decades. Progress in molecular biology and genetic engineering has enabled us to elucidate the mechanisms of collateral growth on the basis of the development of new experimental models and methods for accurate assessment of CCC. These achievements in basic research have been promptly translated into the clinical setting. Interaction between basic and clinical sciences in the fascinating field of CCC will contribute to the establishment of innovative collateral-promoting therapy for severe coronary artery disease.
\end{abstract}

Copyright $\odot 2011$ S. Karger AG, Basel

\section{Introduction}

Coronary collateral circulation (CCC) is an alternative circuit that conveys blood to the ischemic myocardium perfused by a severely stenosed or occluded coronary ar- tery $[1,2]$. Augmentation of the flow reserve of CCC is an attractive therapeutic approach for patients who are not suitable for clinically available revascularization procedures [3]. Rapid progress in basic and clinical research has been made by the development of new animal models for coronary collateral functional growth, exploitation of accurate quantitative assessment of CCC and establishment of conceptual frameworks for coronary collateral recruitment and growth. Recent advances in medical technology, molecular biology and genetic engineering have largely contributed to the aforementioned progress. In this review, we discuss experimental and clinical studies with a focus on the function of CCC from these points of view and provide future perspectives.

\section{Experimental Models for Coronary Collateral Development}

\section{Ameroid Constrictors}

Investigation of CCC involves the use of animal models. Ameroid constrictors have long been utilized to develop extensive CCC in response to the gradual occlusion of coronary artery [4-6]. Although implantation of an ameroid constrictor to a coronary artery is relatively easy, the degree of vessel constriction, namely, the extent of coronary stenosis, is uncontrollable. Therefore, the dayto-day change in shear stress at the site of preexistent collateral arterioles, which is the main stimulus for devel-

\section{KARGER \\ Fax +41613061234 E-Mail karger@karger.ch} www.karger.com
(C) 2011 S. Karger AG, Basel $0008-6312 / 10 / 1174-0246 \$ 26.00 / 0$

Accessible online at:

www.karger.com/crd
Masatoshi Fujita, MD

Human Health Sciences, Kyoto University Graduate School of Medicine

53 Kawaharacho, Shogoin, Sakyo-ku

Kyoto 606-8507 (Japan)

Tel. +81 75751 3932, Fax +81 75751 3909, E-Mail mfujita@kuhp.kyoto-u.ac.jp 
opment of CCC, may show a wide variation among animals [7].

\section{Brief Repeated Coronary Occlusion}

Franklin and his group [8] investigated the hypothesis that brief repeated coronary occlusion develops a functionally significant CCC in conscious dogs. The hypothesis was inspired by the fact that patients with vasospastic angina have an angiographically demonstrable CCC in the absence of significant coronary stenosis $[9,10]$. In Franklin's model, 2 min of occlusion time and $58 \mathrm{~min}$ of interval between consecutive occlusions were determined to be optimal by the following findings. Longer than $2 \mathrm{~min}$ for the first left circumflex coronary artery (LCCA) occlusion frequently provoked sudden cardiac death due to ventricular fibrillation resulting from ischemia-induced QT prolongation in the absence of a significant CCC [11]. Coronary occlusion longer than 2 min also irritated the conscious dog presumably owing to anginalike chest pain. It took about $1 \mathrm{~h}$ for ischemic myocardium to recover from stunning as shown by the abnormal segmental wall motion in the subendocardium perfused by the occluded coronary artery. The principal characteristic of Franklin's model is that stimulation of coronary collateral growth is a function of the total number of 2-min repeated coronary occlusions [8]. Parenteral injection of heparin decreased the total number of coronary occlusions required for coronary collateral growth to become sufficient for regional myocardial oxygen demand in the area perfused by occluded coronary artery, indicating that heparin potentiates and accelerates coronary collateral development $[12,13]$. Since a canine model may have an advantage compared with a rodent model in terms of quantification of stimulation, it seems important to employ Franklin's model to test candidate drugs for accelerating coronary collateral growth before clinical application.

\section{Assessment of Coronary Collateral Function}

\section{Myocardial Ischemia during Coronary Artery \\ Occlusion}

Coronary collateral function as a blood-conveying circuit has been evaluated indirectly by the extent of ischemia of jeopardized myocardium perfused by an occluded collateral-receiving coronary artery. In Franklin's canine model of coronary collateral development, we utilized parameters indicating the extent of myocardial ischemia such as regional myocardial systolic wall mo- tion $[8,14,15]$, ST-segment elevation recorded using ultrasonic dimension gauges implanted in the subendocardial layer of potentially ischemic area [14] and reactive hyperemic response after the release of brief coronary occlusion $[8,14,15]$. Monitoring of the changes in these parameters was useful for assessing the coronary collateral development on a day-to-day basis $[8,14,15]$. Moreover, all the three parameters indicative of myocardial ischemia correlated well with coronary collateral blood flow $[14,16]$. In the clinical setting, brief coronary occlusion by an angioplasty balloon catheter provides an opportunity to assess collateral function. The degree of collateral filling during balloon inflation has been found to correlate significantly with both left ventricular (LV) regional wall motion and the sum of ST-segment elevation measured on a 12-lead ECG $[17,18]$.

\section{Collateral-Dependent Regional Myocardial Blood Flow}

Regional myocardial blood flow in the collateral-dependent area has long been a gold standard of coronary collateral blood flow. Using radioactive microspheres, Becker and Pitt [5] found that regional myocardial blood flow in the area perfused by the gradually occluded LCCA (by the ameroid constrictor) was comparable with regional myocardial blood flow in the nonoccluded left anterior descending coronary artery (LAD) perfusion area. To overcome the limitation of usage of radioactive microspheres resulting from institutional restrictions on isotope handling, colored microspheres have been developed and utilized in experimental studies related to CCC [19]. Clinically, exercise and resting thallium-201 myocardial scintigraphy was utilized to quantitatively evaluate regional myocardial blood flow in the collateral-dependent area $[20,21]$. We also applied ${ }^{99 \mathrm{~m}} \mathrm{Tc}$-tetrofosmin to demonstrate that a serotonin blocker, sarpogrelate, increases coronary collateral blood flow to the area perfused by the completely occluded coronary artery [22]. Myocardial contrast echocardiography was reported to be a useful method for assessing not only regional wall motion, but also coronary collateral blood flow, in recent myocardial infarction (MI) patients with completely occluded infarct-related coronary artery [23].

\section{Total Coronary Collateral Blood Flow Velocity}

To quantitatively evaluate total coronary collateral blood flow from the LCCA to the area perfused by an occluded LAD, we placed another occluder around the proximal LAD in Franklin's model (fig. 1) [16]. In the presence of well-developed CCC, LCCA flow was prompt- 


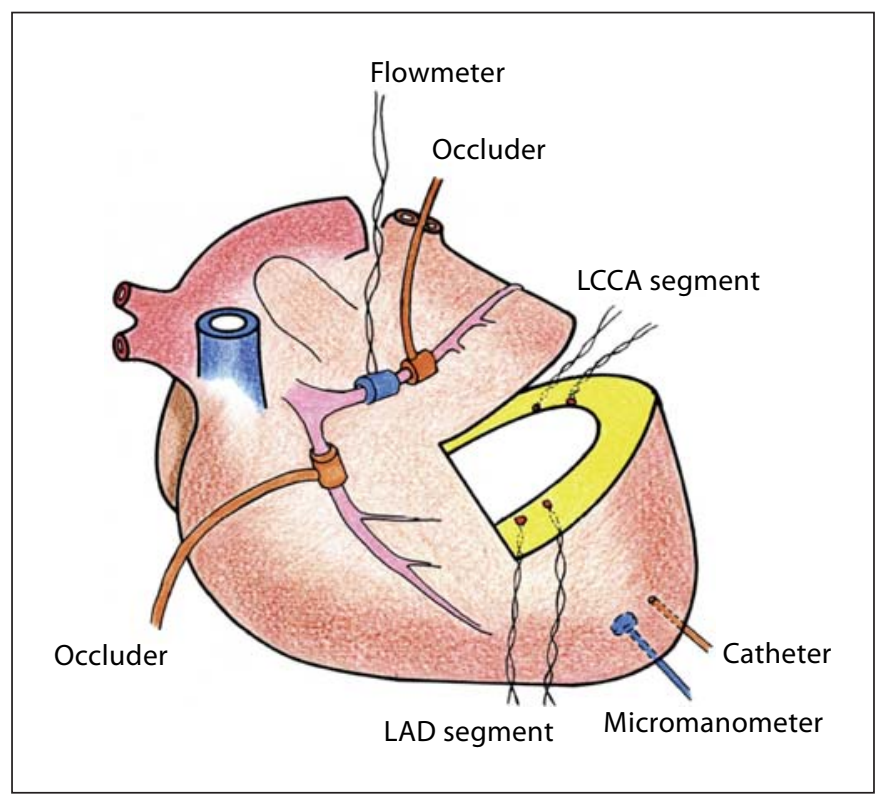

Fig. 1. Modified Franklin's 2-min coronary occlusion canine model showing instrumentation. A high-fidelity micromanometer and a saline-filled catheter were inserted into the left ventricular cavity for measuring left ventricular pressure. Two pairs of ultrasonic crystals were implanted for measuring subendocardial segment lengths in the areas perfused by the LAD and LCCA. An ultrasonic pulsed Doppler flowmeter was positioned around the LCCA. Two externally inflatable pneumatic cuff occluders were installed around the proximal parts of LAD and LCCA. Two-min LCCA occlusions were repeated 8 times daily at intervals of 60 min until functionally significant collateral development. After that, LAD was occluded for 2 min to evaluate retrograde collateral blood flow from the LCCA to the area perfused by the occluded LAD.

ly increased by the LAD occlusion and returned to the preocclusion baseline level upon an abrupt release of LAD occlusion (fig. 2). However, in the absence of a functionally significant CCC, the step reduction in LCCA flow upon an abrupt release of LAD occlusion was less clear, presumably because coronary collateral blood flow as well as flow to the LCCA perfusion area increased due to increased myocardial oxygen demand in the LCCA area during LAD occlusion [16]. Thus, LCCA flow during LAD occlusion is the sum of LCCA to LAD collateral flow and flow to the area perfused by LCCA. To distinguish the step reduction in LCCA flow, abrupt release of an LAD occluder was mandatory in the canine model [16].

These experimental findings were translated to the clinical setting. Blood flow velocity in the contralateral coronary artery was continuously monitored using a

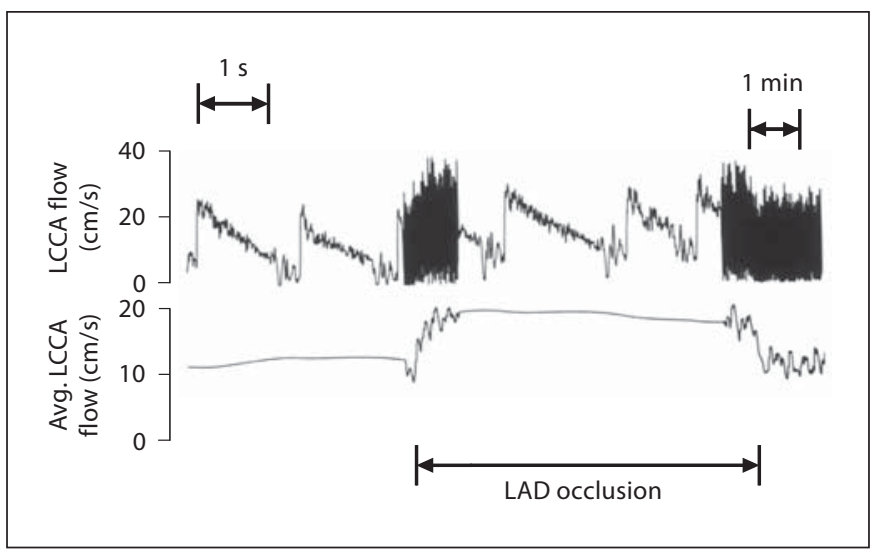

Fig. 2. Recordings of measurement of coronary collateral blood flow. When the LAD was occluded after collateral development, LCCA flow velocity increased by approximately $60 \%$. Following the release of the LAD occlusion, LCCA flow abruptly decreased to the preocclusion level. The abrupt reduction in LCCA flow upon release of the LAD occlusion was considered to be a quantitative measure of collateral perfusion from the LCCA to the area normally perfused by the LAD.

Doppler catheter or Doppler guide wire before, during and after ipsilateral coronary artery occlusion [24, 25]. Angiographic visualization of the extent of CCC correlated well with the percent increase in blood flow velocity in the collateral-providing contralateral artery during the occlusion of collateral-receiving artery. Different from the canine study, the heart rate remained unchanged during 1-2 min of coronary occlusion despite the appearance of myocardial ischemia resulting from absent or poor CCC. Compensatory hyperkinesia of the nonischemic myocardium perfused by the collateral-providing artery was observed in the canine heart [16], which, however, was not the case in humans [26]. Thus, although an abrupt release of coronary balloon occlusion is difficult, it may be unnecessary in human studies. However, this approach has several limitations. First, since increased flow velocity in the collateral-providing artery is accompanied by a potential increase in the caliber at the site of velocity measurement, actual collateral volume flow may be underestimated. Second, collateral flow in the collateral-receiving artery comes from more than one contralateral collateral-providing artery; therefore, coronary arterial wedge pressure may be a better index for total CCC [27]. Finally, accurate assessment of coronary flow velocity is limited because of technical difficulties with appropriate positioning of the catheter or guide tip inside collateral-providing coronary artery. 
Intracoronary Pressure Distal to Coronary Occlusion

Elliot et al. [4] were the first to successfully record a gradual rise in peripheral LCCA pressure induced by a severe degree of coronary stenosis using ameroid constrictors in conscious dogs. It was subsequently confirmed that continuous measurement of peripheral LCCA pressure is a useful method to monitor coronary collateral growth [6]. Clinically, Probst et al. [27] found a positive relationship between distal pressure during angioplasty balloon occlusion and extent of collateral circulation evaluated angiographically. Pijls et al. [28] advocated that intracoronary distal pressure measured using an ultrathin guide wire at maximum vasodilation provides a quantitative measure of coronary collateral flow reserve. Good agreement between the calculated collateral flow indices using velocity or pressure has been reported [29]. Thus, at present, the most reliable and quantitative measure of coronary collateral function in human subjects appears to be the distal pressure-derived collateral flow index (CFI), even though the index is not available in the presence of chronic total occlusion.

\section{Myocardial Viability}

When considering the relationship between CCC and myocardial viability, the following issues must be kept in mind. First, CCC is accurately assessed only in the presence of a pressure gradient between the collateral-providing and collateral-receiving coronary arteries [18]. Therefore, CCC to the area perfused by the occluded coronary artery should be evaluated by the various methods described above. Second, myocardial viability is not only a result of well-developed CCC, but also a cause of further development of CCC [21]. The presence of well-developed CCC at the time of acute coronary occlusion predicts the presence of some viable myocardium. In fact, we have reported that well-developed CCC in acute myocardial infarction (AMI) patients prevents $\mathrm{LV}$ aneurysm formation even in the case of failure of recanalization of the infarctrelated coronary artery [30]. It has been elegantly demonstrated that the existence of viable myocardium, as shown by contrast myocardial echocardiography, predicts functional recovery after successful recanalization procedures in patients with recent MI [23]. On the other hand, in the absence of myocardial viability, microcirculation in the collateral-dependent myocardium is jeopardized, resulting in decreased collateral blood flow, a main stimulus for collateral growth $[3,7]$. Thus, in patients with nonviable myocardium, such as LV aneurysm, further coronary collateral development may not be expected. Coronary collateral development after AMI is deter-

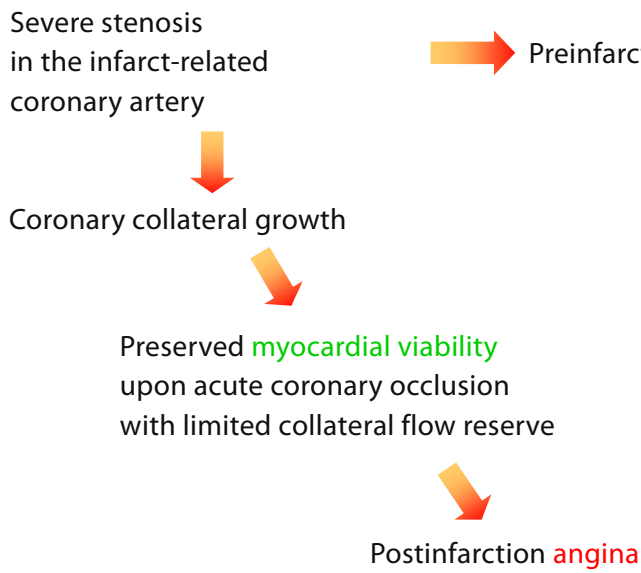

Fig. 3. Relationships among CCC, pre- and postinfarction angina and myocardial viability.

mined by the presence or absence of viable myocardium, itself determined by the extent of CCC at the time of AMI $[31,32]$.

Relationships among CCC and myocardial ischemia, namely angina pectoris and myocardial viability, are shown in figure 3 . Severe coronary narrowing induces angina and a pressure gradient between the collateralproviding and collateral-receiving coronary arteries, which triggers collateral growth as a result of increased shear stress at the site of preexistent collateral arterioles $[3,7]$. A robust CCC induced by the above-mentioned mechanisms contributes to the preservation of LV function in AMI patients even in the absence of successful recanalization procedures [33]. In these patients, the salvaged viable myocardium may become a substrate for postinfarction angina because of a limited coronary collateral flow reserve [34]. Taken together, myocardial viability and CCC seem to be two sides of the same coin.

\section{Considerations for Unsolved Issues Related to CCC}

\section{Regression of CCC}

Coronary collateral regression is divided into functional and anatomical regression. Functional regression means that collateral blood flow is not sufficient despite the anatomical presence of collateral vessels. Collateral vessels gradually dilate after the establishment of a pressure gradient across the collateral network, presumably due to flow-dependent nitric oxide release [35]. Another 
characteristic of Franklin's model is that functional and anatomical regression of CCC can be assessed separately. We found that it requires approximately 6-8 min to completely recruit collateral circulation during more prolonged coronary reocclusion following 1 week of reflow [36]. The functional regression depends on the interval between repeated coronary occlusions. With increased interval, delayed regional myocardial functional recovery was observed owing to delayed opening of the functionally regressed collateral vessels. Clinically, we demonstrated regression of the collateral circulation following successful percutaneous transluminal coronary angioplasty for severe coronary stenosis in patients with angina [37]. Elevation of the ST segment in a standard 12lead ECG after $1 \mathrm{~min}$ of balloon inflation averaged 0.19 $\pm 0.17 \mathrm{mV}$ at repeat percutaneous transluminal coronary angioplasty, which was significantly higher than $0.13 \pm$ $0.25 \mathrm{mV}$ at baseline. Although these data suggest collateral regression, it is difficult to differentiate functional from anatomical regression following 125 days of reflow, because $1 \mathrm{~min}$ of balloon inflation appears to be too short [37]. Collateral functional regression can be summarized as follows. Well-developed collateral vessels close upon disappearance of a pressure gradient across the collateral network, and it takes several minutes to reopen the closed collateral vessels after reestablishment of the pressure gradient. The longer the interval between coronary occlusions, the longer the time required for full collateral functioning. Another important factor for collateral functional regression is the fact that newly developed collateral vessels are prone to vasospasm due to endothelial dysfunction [38]. Indeed, several investigators reported angiographic disappearance of well-developed CCC during selective intracoronary injection of ergonovine or acetylcholine [39-41]. Taken together, both the gradual dilation and the vasospasm responsible for collateral functional regression may be partly explained by immature endothelial function of newly developed collateral vessels.

Apart from collateral functional regression, collateral anatomical regression remains controversial. We have shown that newly developed collateral vessels serve as significant blood-conveying conduits upon coronary reocclusion after 15 weeks of reflow [36]. Khouri et al. [42] also observed a lack of anatomical regression of well-developed collateral vessels. When the coronary artery was reoccluded after 3-90 days of reflow, the intracoronary pressure at the distal site of the occluder increased progressively to the same levels observed during coronary occlusion just prior to the establishment of reflow. In con- trast, Eckstein [43] reported that collateral circulation produced by severe anemia regressed with correction of the anemia. These divergent results may be, at least in part, explained by the extent of collateral growth as the degree of increased collateral blood flow secondary to anemia may be much less than following coronary occlusion $[3,7]$. Incompletely matured collateral vessels may be prone to anatomical regression. In fact, Yamakado et al. [44] reported a case of AMI resulting from anatomical regression of previously developed collateral vessels. This angiographically documented anatomical regression occurred within 1 month after reflow of the infarct-related coronary artery. In this case, functional regression seems unlikely as intracoronary injection of nitroglycerin did not visualize anatomically regressed CCC. The concept that immature collateral vessels do regress anatomically has been substantiated with the use of more sophisticated methods for functional evaluation of CCC [45]. At approximately 5 months after successful recanalization for chronic total occlusion, Doppler and pressure-derived collateral functional indexes decreased considerably during 3-min balloon occlusion in patients with initially immature collaterals. Such an occlusion should be sufficient for full recruitment of functionally regressed CCC, as indicated by only a slight decrease in functional indexes in patients with initially well-developed collaterals.

\section{Effect of CCC on Survival}

The presence of well-developed CCC contributes to regional functional preservation in the myocardium perfused by a severely stenosed coronary artery, leading to the hypothesis that the presence of CCC improves prognosis of patients with coronary artery disease (CAD). On the other hand, because a variety of predictors for survival of CAD patients, such as age, sex, disease severity, and comorbidities, also affect the development of CCC [46], the relationship between the presence of CCC and survival of CAD patients is complicated. To clarify this, clinical investigations with appropriate statistical analyses for a large number of CAD patients are necessary. Therefore, this review focuses only on large-scale clinical studies.

The Osaka Acute Coronary Insufficiency Study (OACIS) group reported that, among 1,934 AMI patients with completely occluded infarct-related artery, angiographic absence of recruitable CCC to the infarct-related artery in patients above 70 years of age is an independent predictor of in-hospital death after adjustment for various other predictors of the end point [47]. The presence of spontaneous visible CCC on coronary angiography was asso- 
ciated with a favorable effect on a composite end point comprising $\mathrm{MI}, \mathrm{CAD}$ death and revascularization at 24-month follow-up in 879 male CAD patients, after adjustment for possible confounding factors [48]. Meanwhile, the protective effect of spontaneously visible collaterals was slightly but not statistically significantly reduced in patients with multivessel disease, those with prior MI and those with coronary artery bypass grafting [48]. With the use of a coronary pressure-derived CFI, Meier et al. [49] evaluated the functional status of recruitable collaterals and their prognostic benefit in 845 patients who were followed up for 10 years. The incidence of cardiac death was 4 -fold higher in patients with insufficient CCC $(\mathrm{CFI}<0.25)$ compared to those with sufficient CCC (CFI $\geq 0.25$ ). Multivariate analysis revealed that age, low CFI and current smoking were independent predictors of cardiac mortality. Because a pressure gradient across the collateral network is indispensable for the accurate assessment of collateral function, quantitative assessment of the functional status of recruitable collaterals seems more appropriate for investigation of the prognostic impact of CCC as opposed to angiographic assessment of spontaneously visible collaterals $[17,18,48]$. Another interesting finding of the study was the lack of any difference in the incidence of AMI between the 2 groups of patients. This suggests that CCC serves as a significant circuit to convey blood to the myocardium perfused by an acutely occluded coronary artery for a long period of time, even if partially anatomically regressed CCC cannot prevent the occurrence of AMI [49]. Moreover, because CCC is a bidirectional blood-conveying circuit $[16$, 50], preexistent collaterals function bidirectionally for attenuating myocardial ischemia irrespective of the culprit lesion of AMI.

\section{Future Perspectives of Studies on CCC}

One of the goals of clinical medicine is the establishment of new therapies for intractable diseases, and collateral-promoting therapy for intractable coronary artery disease is a candidate for new treatment modalities. Exercise training is effective for collateral growth; however, accompanying myocardial ischemia is inevitable, which may provoke malignant arrhythmias. Treatments to mechanically increase coronary collateral blood flow without unfavorable effects on regional myocardial oxygen consumption seem more promising.

\section{Acknowledgment}

We are very grateful to Yukiko Okumura for her extraordinary help in the preparation of the manuscript.

\section{References}

1 Sasayama S, Fujita M: Recent insights into collateral circulation. Circulation 1992;85: 1197-1204.

-2 Fujita M, Tambara K: Recent insights into human coronary collateral development. Heart 2004;90:246-250.

>3 Fujita M, Sasayama S: Coronary collateral growth and its therapeutic application to coronary artery disease. Circ J 2010;74:12831289.

$\checkmark 4$ Elliot EC, Jones EL, Bloor CM, Leon AS, Gregg DE: Day-to-day changes in coronary hemodynamics secondary to constriction of circumflex branch of left coronary artery in conscious dogs. Circ Res 1968;22:237-250.

5 Becker LC, Pitt B: Collateral blood flow in conscious dogs with chronic coronary artery occlusion. Am J Physiol 1971;221:1507-1510.

6 Longhurst JC, Ordway GA, Buja LM: Evaluation of coronary native and coronary collateral pressure gradients in the conscious dog. Am J Cardiovasc Pathol 1986;1:79-90.

$\checkmark 7$ Schaper W: Collateral circulation: past and present. Basic Res Cardiol 2009;104:5-21.
8 Fujita M, McKown DP, McKown MD, Hartley JW, Franklin D: Evaluation of coronary collateral development by regional myocardial function and reactive hyperaemia. Cardiovasc Res 1987;21:377-384.

$\checkmark 9$ Takeshita A, Koiwaya Y, Nakamura M, Yamamoto K, Torii S: Immediate appearance of coronary collaterals during ergonovine-induced arterial spasm. Chest 1982;82: 319-322.

10 Tada M, Yamagishi M, Kodama K, Kuzuya T, Nanto S, Inoue M, Abe H: Transient collateral augmentation during coronary arterial spasm associated with ST-segment depression. Circulation 1983;67:693-698.

11 Meier P, Gloekler S, de Marchi SF, Zbinden R, Delacrétaz E, Seiler C: An indicator of sudden cardiac death during brief coronary occlusion: electrocardiogram QT time and the role of collaterals. Eur Heart J 2010;31: 1197-1204.
12 Fujita M, Mikuniya A, Takahashi M, Gaddis R, Hartley J, Mckown D, Franklin D: Acceleration of coronary collateral development by heparin in conscious dogs. Jpn Circ J 1987; 51:395-402.

13 Fujita M, Kihara Y, Hasegawa K, Nohara R, Sasayama S: Heparin potentiates collateral growth but not growth of intramyocardial endarteries in dogs with repeated coronary occlusion. Int J Cardiol 1999;70:165-170.

14 Fujita M, McKown DP, McKown MD, Franklin D: Electrocardiographic evaluation of collateral development in conscious dogs. J Electrocardiol 1988;21:55-63.

15 Yamamoto H, Tomoike H, Shimokawa H, Nabeyama S, Nakamura M: Development of collateral function with repetitive coronary occlusion in a canine model reduces myocardial reactive hyperemia in the absence of significant coronary stenosis. Circ Res 1984;55: 623-632

- 16 Fujita M, McKown DP, McKown MD, Franklin D: Bidirectional function of coronary collateral channels in conscious dogs. Cardiovasc Res 1991;25:58-67. 
17 Cohen M, Rentrop KP: Limitation of myocardial ischemia by collateral circulation during sudden controlled coronary artery occlusion in human subjects: a prospective study. Circulation 1986;74:469-476.

18 Rentrop KP, Cohen M, Blanke H, Phillips RA: Changes in collateral channel filling immediately after controlled coronary artery occlusion by an angioplasty balloon in human subjects. J Am Coll Cardiol 1985;5:587592.

19 Yamamoto T, Suto N, Okubo T, Mikuniya A, Hanada H, Yagihashi S, Fujita M, Okumura $\mathrm{K}$ : Intramyocardial delivery of basic fibroblast growth factor-impregnated gelatin hydrogel microspheres enhances collateral circulation to infarcted canine myocardium. Jpn Circ J 2001;65:439-444.

-20 Rigo P, Becker LC, Griffith LS, Alderson PO, Bailey IK, Pitt B, Burow RD, Wagner HN Jr: Influence of coronary collateral vessels on the results of thallium-201 myocardial stress imaging. Am J Cardiol 1979;44:452-458.

-21 Fujita M, Ohno A, Wada O, Miwa K, Nozawa T, Yamanishi K, Sasayama S: Collateral circulation as a marker of the presence of viable myocardium in patients with recent myocardial infarction. Am Heart J 1991;122:409414.

-22 Tanaka T, Fujita M, Nakae I, Tamaki S, Hasegawa K, Kihara Y, Nohara R, Sasayama $S$ : Improvement of exercise capacity by sarpogrelate as a result of augmented collateral circulation in patients with effort angina. J Am Coll Cardiol 1998;32:1982-1986.

-23 Sabia PJ, Powers ER, Ragosta M, Sarembock IJ, Burwell LR, Kaul S: An association between collateral blood flow and myocardial viability in patients with recent myocardial infarction. N Engl J Med 1992;327:18251831.

24 Kyriakidis MK, Petropoulakis PN, Tentolouris CA, Marakas SA, Antonopoulos AG, Kourouclis CV, Toutouzas PK: Relation between changes in blood flow of the contralateral coronary artery and the angiographic extent and function of recruitable collateral vessels arising from this artery during balloon coronary occlusion. J Am Coll Cardiol 1994:23:869-878.

-25 Piek JJ, van Liebergen RA, Koch KT, Peters RJ, David GK: Comparison of collateral vascular responses in the donor and recipient coronary artery during transient coronary occlusion assessed by intracoronary blood flow velocity analysis in patients. J Am Coll Cardiol 1997;29:1528-1535.

-26 Verani MS, Lacy JL, Guidry GW, Nishimura S, Mahmarian JJ, Athanasoulis T, Roberts R: Quantification of left ventricular performance during transient coronary occlusion at various anatomic sites in humans: a study using tantalum-178 and a multiwire gamma camera. J Am Coll Cardiol 1992;19:297-306.
27 Probst P, Zangl W, Pachinger O: Relation of coronary arterial occlusion pressure during percutaneous transluminal coronary angioplasty to presence of collaterals. Am J Cardiol 1985;55:1264-1269.

28 Pijls NHJ, van Son JAM, Kirkeeide RL, De Bruyne B, Gould KL: Experimental basis of determining maximum coronary, myocardial, and collateral blood flow by pressure measurements for assessing functional stenosis severity before and after percutaneous transluminal coronary angioplasty. Circulation 1993;87:1354-1367.

29 Seiler C, Fleisch M, Billinger M, Meier B: Simultaneous intracoronary velocity- and pressure-derived assessment of adenosineinduced collateral hemodynamics in patients with one- to two-vessel coronary artery disease. J Am Coll Cardiol 1999;34: 1985-1994.

30 Hirai T, Fujita M, Nakajima H, Asanoi H, Yamanishi K, Ohno A, Sasayama S: Importance of collateral circulation for prevention of left ventricular aneurysm formation in acute myocardial infarction. Circulation 1989;79: 791-796.

31 Schwartz H, Leiboff RL, Katz RJ, Wasserman AG, Bren GB, Varghese PJ, Ross AM: Arteriographic predictors of spontaneous improvement in left ventricular function after myocardial infarction. Circulation 1985;71: 466-472.

32 Ejiri M, Fujita M, Sakai O, Miwa K, Asanoi $\mathrm{H}$, Sasayama S: Development of collateral circulation after acute myocardial infarction: its role in preserving left ventricular function. J Cardiol 1990;20:31-37.

33 Hirai T, Fujita M, Yamanishi K, Ohno A, Miwa K, Sasayama S: Significance of preinfarction angina for preservation of left ventricular function in acute myocardial infarction. Am Heart J 1992;124:19-24.

34 Fujita M, Sasayama S, Araie E, Ohno A, Yamanishi K, Hirai T: Significance of pre-infarction angina for occurrence of post-infarction angina. Eur Heart J 1988;9:159-164.

35 Yamanishi K, Fujita M, Ohno A, Sasayama S: Importance of myocardial ischaemia for recruitment of coronary collateral circulation in dogs. Cardiovasc Res 1990;24:271-277.

36 Fujita M, McKown DP, McKown MD, Franklin D: Coronary collateral regression in conscious dogs. Angiology 1990;41:621-630.

- 37 Fujita M, Nakae I, Fudo T, Tanaka T, Iwase T, Tamaki S, Nohara R, Sasayama S: Fate of collateral vessels after successful coronary angioplasty in patients with effort angina. J Am Coll Cardiol 1997;29:544-548.

38 Sellke FW, Quillen JE, Brooks LA, Harrison DG: Endothelial modulation of the coronary vasculature in vessels perfused via mature collaterals. Circulation 1990;81:1938-1947.
39 Yamakado T, Kecheng X, Masuda T, Nakano T, Takezawa H: Disappearance of coronary collateral vessels as a mechanism of vasospastic angina. Am Heart J 1989;117:1379-1381.

-40 Pupita G, Maseri A, Kaski JC, Galassi AR, Gavrielides S, Davies G, Crea F: Myocardial ischemia caused by distal coronary-artery constriction in stable angina pectoris. $\mathrm{N}$ Engl J Med 1990;323:514-520.

-41 Yamanishi K, Fujita M, Miwa K, Igawa A: Effects of intracoronary injection of acetylcholine on coronary collateral circulation. Cathet Cardiovasc Diagn 1993;28:114-118.

42 Khouri EM, Gregg DE, McGranahan GM Jr: Regression and reappearance of coronary collaterals. Am J Physiol 1971;220:655-661.

43 Eckstein RW: Development of interarterial coronary anastomoses by chronic anemia; disappearance following correction of anemia. Circ Res 1955;3:306-310.

44 Yamakado T, Inden M, Oonishi T, Maeda M, Ueda K, Takeuchi M, Nakano T: Development of acute myocardial infarction associated with coronary collateral regression after reperfusion by percutaneous transluminal coronary angioplasty. Heart Vessels 1993;8: 110-113.

- 45 Werner GS, Emig U, Mutschke O, Schwarz G, Bahrmann P, Figulla HR: Regression of collateral function after recanalization of chronic total coronary occlusions: a serial assessment by intracoronary pressure and Doppler recordings. Circulation 2003;108: 2877-2882.

46 Kinnaird T, Stabile E, Zbinden S, Burnett MS, Epstein SE: Cardiovascular risk factors impair native collateral development and may impair efficacy of therapeutic interventions. Cardiovasc Res 2008;78:257-264.

- 47 Kurotobi T, Sato H, Kinjo K, Nakatani D, Mizuno H, Shimizu M, Imai K, Hirayama A, Kodama K, Hori M, OACIS Group: Reduced collateral circulation to the infarct-related artery in elderly patients with acute myocardial infarction. J Am Coll Cardiol 2004;44: 28-34.

48 Regieli JJ, Jukema JW, Nathoe HM, Zwinderman AH, Ng S, Grobbee DE, van der Graaf Y, Doevendans PA: Coronary collaterals improve prognosis in patients with ischemic heart disease. Int J Cardiol 2009;132:257-262.

- 49 Meier P, Gloekler S, Zbinden R, Beckh S, de Marchi SF, Zbinden S, Wustmann K, Billinger $\mathrm{M}$, Vogel R, Cook S, Wenaweser $\mathrm{P}$, Togni M, Windecker S, Meier B, Seiler C: Beneficial effect of recruitable collaterals: a 10 -year follow-up study in patients with stable coronary artery disease undergoing quantitative collateral measurements. Circulation 2007:116:975-983.

50 Miyamoto S, Fujita M, Sasayama S: Bidirectional function of coronary collateral channels in humans. Int J Cardiol 2000;75:249252. 